\title{
Three-Dimensional Screen: A Comprehensive Approach to the Health Monitoring of Zebrafish
}

\author{
Jean-Philippe Mocho
}

\begin{abstract}
Considering the numbers of zebrafish held in the laboratories, it is relevant to develop some tools to monitor the health of the animals, as well as their biotope. Environmental samples can be used to detect aquatic pathogens. Comprehensive health monitoring would thus seek pathogens in three dimensions of the animals and microbes' habitat: the fish, the sludge, and the water. This three-dimensional approach is called the 3D screen and it introduces some complementary tools to routine sentinel screening. For example, sludge and sump swabs analyses allow an efficient detection of pathogens at a low cost and with a fast turnover. These assays are particularly useful in cases of Pseudocapillaria tomentosa infestation or Mycobacterium haemophilum outbreak. Indeed, such a broader choice of diagnostic tests gives flexibility for the veterinarian to investigate Mycobacterium spp. presence in the water systems and fish colonies. Some other robust additional analysis, like the mortality rate monitoring, quickens the decision-making process. The 3D screen describes how this new toolbox can be used efficiently to monitor laboratory fish health.
\end{abstract}

\section{Introduction}

$\mathbf{R}$ ESEARCH BENEFITS FROM the health monitoring of laboratory animals. ${ }^{1,2}$ Detecting the presence of pathogens leads to a better interpretation of experimental results. Monitoring the presence of pathogens allows actions to be taken to improve health and reduce mortality due to disease, as well as improving cost effectiveness of research. Knowing the health status helps to define quarantine procedures when exchanging colonies to refresh wild-type genetic pool or to import new genetically altered lines.

Zebrafish (Danio rerio) are no exception. ${ }^{3-6}$ The health screening often consists in setting sentinels prefiltration and/ or postfiltration. Sentinels and colony animals are tested by histopathology for a general pathology screen and/or by polymerase chain reaction (PCR) to identify a specific pathogen or to screen for a defined panel of pathogens. Exposing prefiltration sentinels to contaminant may increase the animal carer's workload when the sentinels are set in an independent tank receiving sump water. Otherwise, adding a sentinel tank to the recirculating system is sometimes an expensive engineering task. Sentinels need time to be exposed to present pathogens and that restrict the flexibility to test the colonies and the systems when a problem appears. It is not practical when screening imported fish in quarantine. Sending colony animals and sentinels in numbers to detect less prevalent pathogens increases the number of animals used.

We propose in this study a more comprehensive and flexible approach to health monitoring of zebrafish by detecting pathogens in three dimensions of their habitat: the fish, the sludge, and the water. Fish health is monitored by monthly report of mortality. Colony animals with or without clinical signs (found dead or euthanized) are screened to explore the mortality data. Prefiltration sentinels are exposed to contaminant from sumps and screened. Tank sludge is screened for the presence of pathogens, for example, Pseudocapillaria tomentosa eggs. ${ }^{7}$ The water and biofilm are sampled for bacteriology test, for example, Mycobacterium spp. speciation. ${ }^{8}$

This 3D screen proposes a three-dimensional approach to fish health monitoring and it gives some flexibility. When an increase in mortality is detected and sentinels are being exposed, testing the water and the sludge is still a valuable option and it proposes a more comprehensive set of results than just testing colony fish on the system randomly. Water, biofilm, and sludge samples are not time consuming samples to take. Such comprehensive approach may reduce the numbers of animals used to detect the presence of some pathogens. For example, Mycobacterium spp. can be identified, thanks to the biofilm. Analysis of the sludge is a useful

Mill Hill Laboratory, The Francis Crick Institute, London, United Kingdom.

(C) Jean-Philippe Mocho, 2016; Published by Mary Ann Liebert, Inc. This Open Access article is distributed under the terms of the Creative Commons License (http://creativecommons.org/licenses/by/4.0), which permits unrestricted use, distribution, and reproduction in any medium, provided the original work is properly credited. 
tool in quarantine to screen for imported animals without sacrificing any.

The 3D approach is used at the Francis Crick Institute, London, United Kingdom, where the zebrafish facilities mainly support developmental biology projects. The Institute was opened in April 2015 and has been operating across multisite with zebrafish held in two locations from legacy National Institute of Medical Research (MH) and London Research Institute (LIF). Due to the historical development of each site independently over the last 30 years, there is a wide diversity of practices and systems in use. Therefore, we will only detail the relevant information to describe the 3D screen and how we used it to investigate outbreaks in two systems, namely room 8 system 2 at $\mathrm{MH}$ and Aquarium A at LIF. We will see how this comprehensive approach to diagnostics helped in cases of Mycobacterium haemophilum outbreak and $P$. tomentosa infestation. In addition, we will describe the advantages of looking for Mycobacterium spp. in the environment rather than in the fish. Finally, we will detail how the 3D screen can help the decision-making process.

\section{Materials and Methods}

\section{Overview of the fish facilities}

Across the two institute sites, the fish are housed in 25 independent recirculating aquaculture systems (RAS) all fitted with mechanical filters, UV, biofilters, and sometimes with a carbon filter. Altogether, there are 10 different models of holding systems to keep 25,000 adult zebrafish. Most systems, like system 2 in room 8 at $\mathrm{MH}$, are supplied with reverse osmosis water ( $\mathrm{RO})$ and aim for a conductivity of $500 \mu \mathrm{s}, \mathrm{pH} 6.5-8.0$, temperature $26-28^{\circ} \mathrm{C}$, Total Ammonia Nitrogen below $0.6 \mathrm{ppm}$, Nitrite below $0.5 \mathrm{ppm}$, and Nitrate below $100 \mathrm{ppm}$ (Table 1). System 2 was made by Aqua Schwarz GmbH, Gottingen, Germany. Aquarium A at LIF is homemade and it is supplied with filtered and dechlorinated London city water. Aquarium A water parameters are $1300 \mu \mathrm{S}$ conductivity and $\mathrm{pH} 8.4$.

\section{Key husbandry elements}

The zebrafish are only used for egg production, and animals with any clinical sign or over 24 months of age are euthanized. A database to detect lines with adverse effects is in development.

The fish are kept on a constant $14 \mathrm{~h}$ on light cycle/10 h off light cycle. Wild-type fish are bred by mass spawning to supply large clutch to researchers. Embryos are kept in incubators at $27-28^{\circ} \mathrm{C}$ until day 5 postfertilization. At that stage, 50 larval are set on the RAS in a $3.5 \mathrm{~L}$ tank and they are fed paramecium and ZM-000 (Zebrafish Management Ltd, Winchester, United Kingdom) twice daily. Brine shrimp is fed once daily from day 12. Paramecium is stopped at day 25. The ZM pellet size is increased to ZM-100 at day 19, ZM-200 at day 33, and ZM-300 at day 48. At 8 weeks of age, the fish are split in groups of 15 per $3.5 \mathrm{~L}$ tank and they are fed SAFE caviar 300-500 (SAFE, Augy, France) twice daily following a diet transition period with a reduction of brine shrimp supply to once per week.

Regarding biosecurity, the nets are soaked following each use in a solution containing $5 \mathrm{~mL}$ of $0.5 \% \mathrm{NaOCl}$ solution per liter for $15 \mathrm{~min}$. Then, they are thoroughly rinsed and heat treated at $90^{\circ} \mathrm{C}$ for $60 \mathrm{~min}$. All imported fish are reared in quarantine. ${ }^{2}$ Only the eggs are introduced to our conventional systems following surface sanitization according to the ZIRC bleaching protocol. ${ }^{9}$

\section{The $3 D$ screen}

The 3D screen looks for pathogens in three dimensions of the fish and microbe habitat as follows: the fish, the sludge, and the water.

Detecting pathogens in zebrafish. To define mortality rates, animal carers monitor the health of the animals on a daily basis, they euthanize any sick fish, and they record any death of zebrafish older than 8 weeks of age. For each RAS, the number of fish dead in a month is divided by an estimation of the number of fish held on the RAS. A census is performed several times a year and the population size estimation is adjusted according to transfers and mortality.

To screen each room, prefiltration sentinels are used routinely. Due to space and biosecurity constraints, the quarantine system has its own tank of sentinel on the RAS and sump water is added daily to this tank.

Otherwise, sentinels are kept in stand-alone tanks. The density is reduced to 1-2 fish per liter-typical 10-12 fish in an $8 \mathrm{~L}$ tank. The fish are fed once a day and are exposed to all adult diets. Biomedia from the screened systems are added to the sentinel tank to expose the sentinels to this flora and to control better the water quality. Sentinel tank water is replaced on Monday, Wednesday, and Friday by sump water from the screened systems. To optimize Mycobacterium spp. detection, ${ }^{4,10}$ the sentinels are exposed for 4 months and the sentinel screen is performed two to three times a year.

The sentinel group is selected to replicate the aquarium dominant genetic background and to increase the sensitivity for pathogens that are more prevalent in one gender and/or age category. ${ }^{11}$ The sentinels are wild type (mainly $\mathrm{AB}$ ): at least one female and one male below 6 months of age, one female and one male between 6 and 12 months, and one female and one male above 18 months of age.

When sampling is due, the sentinels are euthanized by immersion in an overdose solution of 2-phenoxyethanol

Table 1. Example of Water Quality Parameters for System 2 and Aquarium A

\begin{tabular}{|c|c|c|c|c|c|c|c|c|}
\hline \multirow[b]{2}{*}{ System } & \multirow[b]{2}{*}{$p H$} & \multirow[b]{2}{*}{ Conductivity $(\mu S)$} & \multicolumn{5}{|c|}{$m g / L$} & \multirow[b]{2}{*}{ Water supply } \\
\hline & & & $T A N$ & Nitrite & Nitrate & $G H$ & $K H$ & \\
\hline System 2 & 7.0 & 500 & 0 & 0 & 73 & 51 & 36 & $\mathrm{RO}$ \\
\hline Aquarium A & 8.4 & 1300 & 0 & 0 & 120 & 306 & 196 & MAINS \\
\hline
\end{tabular}

$\mathrm{GH}$, hardness; $\mathrm{KH}$, alkalinity; RO, reverse osmosis; TAN, total ammonia nitrogen. 


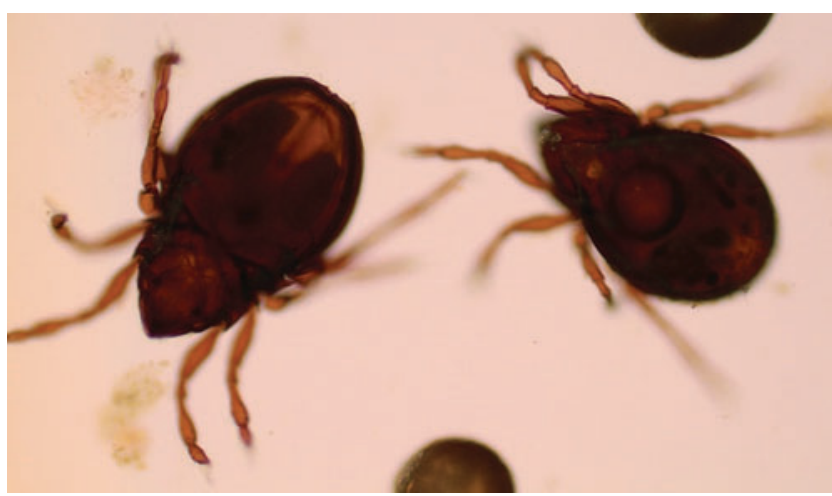

FIG. 1. Arthropods detected by microscopy during sludge analysis $(40 \times)$.

$(3 \mathrm{~mL} / \mathrm{L})$ for $10 \mathrm{~min}$. For some fish, wet mounts ${ }^{12}$ (gill, mucus, scale, and fin) and in-house histopathology are performed (at least hematoxylin and eosin and acid-fast staining). These techniques help for the surveillance of unexpected and/or unknown pathogens. A minimum of three sentinels are sent to a commercial diagnostic laboratory for some specific PCR assays.

Zebrafish are often pooled for PCR and the list of tested pathogens is sometimes as comprehensive as possible: M. haemophilum, Mycobacterium marinum, P. tomentosa, Edwardsiella ictaluri, ${ }^{13}$ Ichthyophthirius multifiliis, ${ }^{14} \mathrm{Pisci}$ noodinium pillulare, ${ }^{15}$ Pleistophora hyphessobryconis, ${ }^{16}$ Flavobacterium columnare, ${ }^{17}$ infectious spleen and kidney necrosis virus, ${ }^{18}$ Mycobacterium abscessus, Mycobacterium chelonae, Mycobacterium fortuitum, Mycobacterium peregrinum, and Pseudoloma neurophilia.

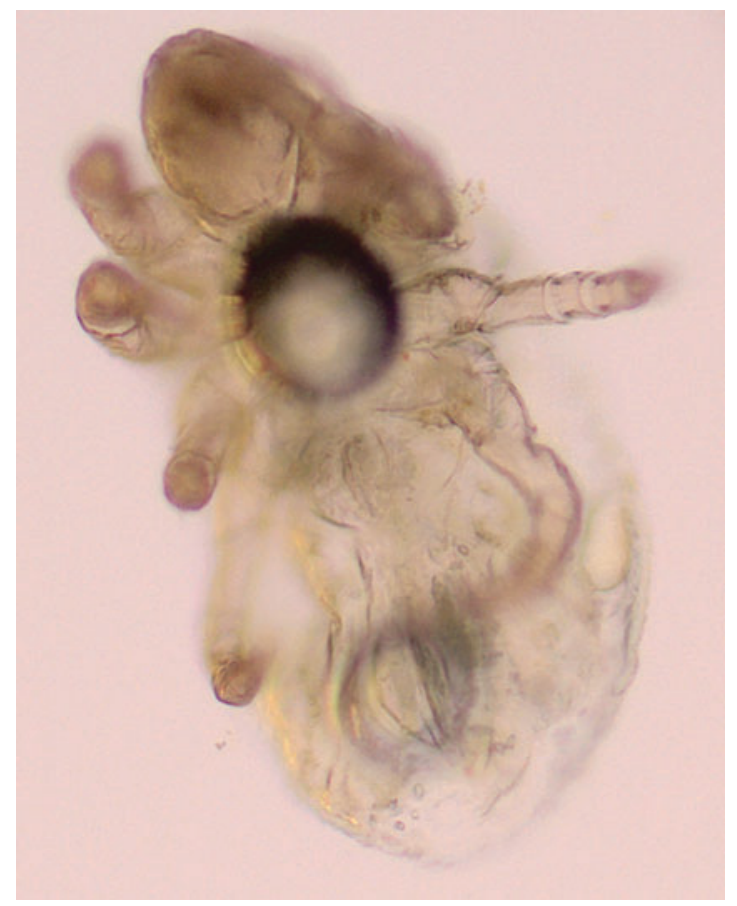

FIG. 2. Arthropods detected by microscopy during sludge analysis $(40 \times)$.

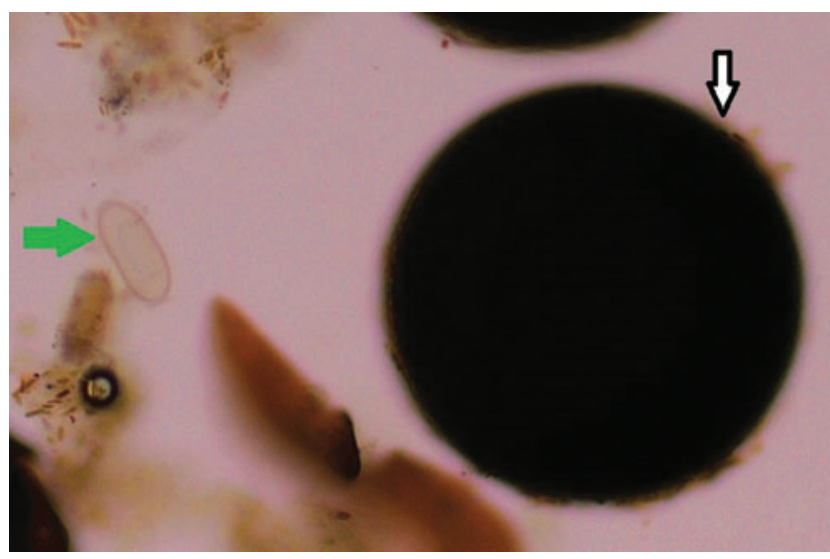

FIG. 3. Pseudocapillaria tomentosa egg next to artemia egg as seen during microscopic screening of sludge $(200 \times)$. Green arrow $=P$. tomentosa egg; white arrow $=$ artemia egg.

Detecting pathogens in the sludge. The analysis of the sludge can be performed to monitor the diverse population in the RAS biotope: algae, arthropods (Figs. 1 and 2), and mycobacterial biofilm. In this study, we detail the technique to detect $P$. tomentosa eggs ${ }^{7}$ (Figs. 3 and 4).

A $60 \mathrm{~mL}$ syringe is used to aspirate the sludge at the bottom of a holding tank. The sample is divided in $15 \mathrm{~mL}$ tubes and centrifuged at $1500 \mathrm{rpm}$ for $10 \mathrm{~min} .{ }^{19}$ The tubes are decanted and filled in half with sugar saturated solution (454 g granulated sugar mixed in $355 \mathrm{~mL}$ hot water). The sediment is stirred well before placing the tubes in the centrifuge swinging buckets. More sugar saturated solution is added to reach the top of the tube. A cover glass is set on top of the tube and in contact with the sugar saturated solution. The tubes are centrifuged at $1500 \mathrm{rpm}$ for $10 \mathrm{~min}$. To read the assay, the cover glass is lifted and placed on a glass slide.

A microscope is used to seek $P$. tomentosa eggs. They are easily identifiable with their bipolar plugs (Fig. 4) and their size (57-78 $\mu \mathrm{m}$ long and $27-39 \mu \mathrm{m}$ diameter). ${ }^{20,21}$

Detecting pathogens in the water. Water samples can be used to detect $P$. neurophilia as described by Whipps and Kent. $^{22}$ In this study, we describe how to monitor the RAS bacterial load and to specify the mycobacterial biofilm.

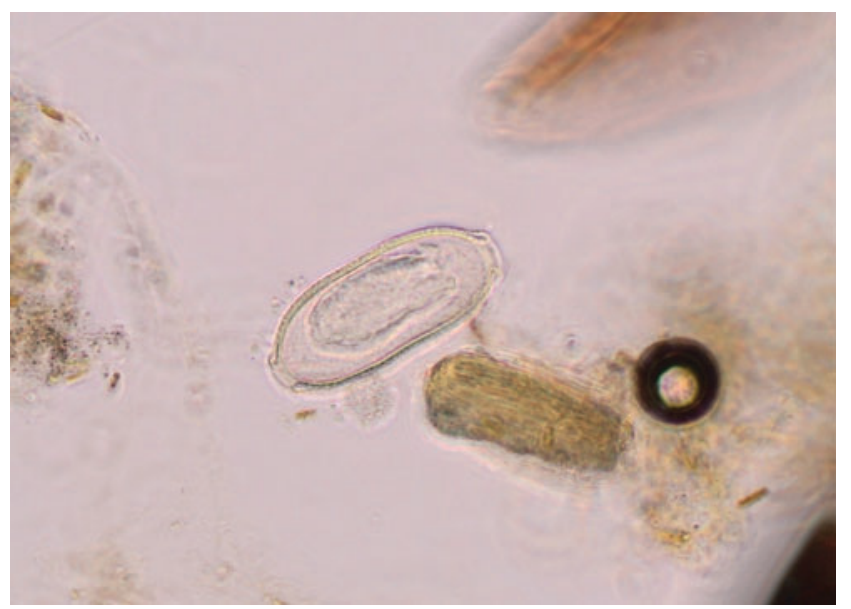

FIG. 4. Zoom on P. tomentosa egg from Figure $3(400 \times)$. 
TABle 2. PCR IDENTIFICATION OF MYCOBACTERIUM SPP. IN Fish AND IN Sump Swabs in 2015 at MH

\begin{tabular}{|c|c|c|c|c|}
\hline \multicolumn{2}{|c|}{83 fish tested } & \multirow[b]{2}{*}{ Mycobacterium spp. } & \multicolumn{2}{|c|}{14 sump swabs } \\
\hline Positive & $\%$ & & $\%$ & Positive \\
\hline 6 & 7 & M. chelonae & 57 & 8 \\
\hline 3 & 4 & M. haemophilum & 29 & 4 \\
\hline 0 & 0 & M. fortuitum & 71 & 10 \\
\hline 0 & 0 & M. peregrinum & 7 & 1 \\
\hline 0 & 0 & M. abscessus & 0 & 0 \\
\hline 0 & 0 & M. marinum & 0 & 0 \\
\hline
\end{tabular}

Percentage is obtained by dividing the number of positive results for each species by the number of tested samples. Note that this does not include the samples taken to confirm M. haemophilum infection in fish during the system 2 outbreak.

$\mathrm{PCR}$, polymerase chain reaction.

To monitor husbandry and UV filtration, bacterial counts of system water are performed thrice a year. The samples are taken aseptically in the sump or post-UV filtration. Bacterial counts are performed by serial dilutions on nutrient agar following $48 \mathrm{~h}$ of incubation at $30^{\circ} \mathrm{C}$. Any suspicious growth during culture is identified and archived.

To identify the Mycobacterium spp. present in the systems, the sump wall is swabbed at the water surface on $5-10 \mathrm{~cm} .^{8}$ Thrice a year, commercial diagnostic laboratories test the swabs by PCR for presence of Mycobacterium spp. and, in case of positive, for identification of the six reported zebrafish pathogens $^{23}:$ M. marinum, M. haemophilum, M. abscessus, $M$. chelonae, M. fortuitum, and $M$. peregrinum.

\section{Results}

The results of this health monitoring approach allowed us to define and confirm the health status of our two main zebrafish facilities. The following pathogens have never been detected: M. marinum, E. ictaluri, I. multifiliis, $P$. pillulare, $P$. hyphessobryconis, $F$. columnare, and infectious spleen and kidney necrosis virus. $P$. neurophilia is present on both sites. One site is infested by $P$. tomentosa and the results of Aquarium A are detailed below. The other site is contaminated by $M$. haemophilum and we will describe how the mortality recording results were used to manage an outbreak in room 8 system 2 . First, we will compare the results on mycobacterial speciation by testing fish versus testing the sump swabs.

In 2015, for the routine screens of the main site, we sampled 83 fish and 14 sump swabs to be tested by PCR for Mycobacterium spp. identification by commercial diagnostic labo- ratories (Table 2). Only nine fish were PCR positive for Mycobacterium spp. and that includes three sentinel fish during a $M$. haemophilum outbreak. Note that other fish results specific to this outbreak are not included in this data. Out of the 14 sump swabs tested by PCR, 23 Mycobacterium spp. were identified. $M$. fortuitum was never identified in a fish, but it is the most prevalent finding in the sump. M. haemophilum was identified twice in quarantine and once in system 2.

While trends are reviewed continuously, our threshold to trigger veterinary investigation is a mortality rate above $1 \%$ for two consecutive months. In room 8, system 2 had an increased mortality rate of $1.81 \%$ in August 2015, thrice more than any other system in room 8 during that period (Table 3 ). Eight fish were euthanized and histopathology revealed widespread granulomas and acid-fast bacilli in four animals (50\%). The sentinels had been euthanized in July and they had not displayed any clinical signs, although 50\% (3/6) of them were PCR positive for $M$. haemophilum. In August, the room sumps and some fish from system 2 were sampled randomly. Fifty percent (8/16) of system 2 fish were PCR positive for $M$. haemophilum. System 2 sump was the only positive for $M$. haemophilum out of the five in the room. This pathogen had been identified in this facility previously, ${ }^{24}$ but it was the first time we had to take action against it and we shut the system down. Some new sentinels were set in August for the whole room. In the December screen, we could not detect $M$. haemophilum in the room sumps and in any sentinel $(0 / 5)$. All along these investigations, the fish samples were PCR negative for M. marinum, Edwardsiella ictaluri, F. columnare, $P$. hyphessobryconis, and $P$. neurophilia. The sump samples were negative for $M$. marinum. And the general bacterial load of the systems did not display any significant increase, staying within the $10^{3}-10^{5} \mathrm{cfu} / \mathrm{mL}$ range.

The first screen performed in Aquarium A on wild-type fish selected randomly revealed the presence of $P$. tomentosa. Two fish were positive by PCR and the results were supported by histopathology in these fish. More tests were requested to confirm the infestation. Altogether, 11 fish were tested by PCR in a commercial diagnostic laboratory and three were PCR positive. Concomitantly, 14 tanks due to be cleaned were selected for the presence of abundant sludge. Their sludge was analyzed and $P$. tomentosa eggs were seen by microscopy in 13 out of the 14 sludge samples (Table 4 ).

\section{Discussion}

The 3D screen approach allows us to health screen routinely our zebrafish colonies. The detection of Mycobacterium

Table 3. Room 8 Mortality Records July and August 2015

\begin{tabular}{|c|c|c|c|c|c|}
\hline \multirow{2}{*}{$\begin{array}{l}\text { Room } 8 \\
\text { System }\end{array}$} & \multirow{2}{*}{$\frac{\text { Last census }}{\text { Total number of fish }}$} & \multicolumn{2}{|c|}{ July '15 } & \multicolumn{2}{|c|}{ August'15 } \\
\hline & & Found dead+sick & Mortality (\%) & Found dead+sick & Mortality (\%) \\
\hline 1 & 1778 & 9 & 0.51 & 5 & 0.28 \\
\hline 2 & 2158 & 27 & 1.04 & 39 & 1.81 \\
\hline 3 & 1653 & 4 & 0.24 & 7 & 0.42 \\
\hline 4 & 1015 & 7 & 0.69 & 6 & 0.59 \\
\hline 5 & 1945 & 10 & 0.51 & 7 & 0.36 \\
\hline
\end{tabular}

For each system, monthly mortality percentage is obtained by dividing the number of found dead and euthanized zebrafish during the month by the estimation of the total number of fish in the system.

Bold figures signify mortality above $1.00 \%$. 
Table 4. Detection of PSeUdocapillaria tomentosa In Aquarium A

\begin{tabular}{|c|c|c|c|c|c|}
\hline \multicolumn{3}{|c|}{ Fish tested by PCR } & \multicolumn{3}{|c|}{ Tank sludge analyses } \\
\hline Number & Positive & $\%$ & Number & Positive & $\%$ \\
\hline 11 & 3 & 27 & 14 & 13 & 93 \\
\hline
\end{tabular}

Percentage is obtained from number of positive results divided by number of tests.

spp. seems to be helped with the sump swabs and this is a useful technique to define a health status. Regarding mycobacterial disease monitoring, the presence of Mycobacterium spp. in the environment is not significant. Only histopathology is able to determine if a fish PCR positive for Mycobacterium spp. is affected and this technique remains key to result interpretation. It is relevant to keep testing the fish to monitor the incidence of mycobacterial contamination since it can be linked with an increase of mortality, as in the outbreak described in this study.

This $M$. haemophilum example shows how a comprehensive approach can quicken the decision-making process. First, the mortality records supported the animal carers' suspicion that fish were not healthy in that system. However, we could not rely on the sentinels to confirm the suspicion. The high incidence of $M$. haemophilum in system 2 fish seemed unusual

\section{Decision Making Process with 3-D screen}

CASE 1: No unwanted pathogens detected when screening sentinels AND

Monthly mortality rate is below $1 \%$ in every system

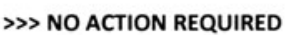

Note: To build up data on the system flora, you can sample sumps, water and fish for bacteriology. Screening the environment is low cost.

CASE 2 Monthly mortality rate is above $1 \%$ for two consecutive months $\gg$ \TAKE ACTION

- Check water quality

- Have you changed anything husbandry wise?

- Do the fish display clinical signs that could orienteer the veterinary investigation?

- Do the sentinels display any clinical signs?

- Sample sick and healthy fish for histo-pathology

- Perform bacteriology culture on sick fish

- Check the system's environment by sludge analysis and sump swab PCR

- Perform PCR on sick and healthy fish

CASE 3:

New Mycobacterial contamination is suspected

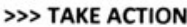

- Swab the sump and identify Mycobacterium spp by PCR

- Confirm mycobacterial disease by histo-pathology and fish mycobacterial PCR identification

CASE 4: P. tomentosa or ectoparasite contamination is suspected \> TAKE ACTION

- Analyse the sludge to confirm contamination

FIG. 5. Decision-making process with 3D screen. in our facilities and M. haemophilum is not often detected in the sumps either. It is the accumulation of data from the various sample types that sped the investigation up.

Similarly, the sludge analysis is a very fast tool to detect $P$. tomentosa eggs. The advantages of the technique compared with histopathology and PCR are the turnover (30 min) and the low cost. The high sensitivity reached in Aquarium A results reflects the bias at sample selection: the fish had been held in these tanks for a prolonged period. It is doubtful that such sensitivity would have been obtained with fish set in clean new tanks; this is a limit for the use of sludge analysis in quarantine.

Following investigation, it is likely that the increase of mortality and M. haemophilum incidence in room 8 system 2 was due to an attempt to feed the fish more. The animals were fed more than usual for a few months before the outbreak while the cleaning and husbandry routine remained unchanged. We suspect that this disturbed the biofilm and/or the fish flora and we changed our diet to the one described above. The general bacterial load monitoring did not allow any further confirmation of a husbandry issue or a general bacterial load increase. But, earlier in 2015, following this feed increase, we detected some cases of bacterial aero cystitis and septicemia. Aeromonas spp., Pseudomonas spp., and Vibrio cholerae non $\mathrm{O} 1$ were cultured from these fish. ${ }^{25} \mathrm{M}$. haemophilum would then strike later, like an opportunistic pathogen, as the infection often requires more time to develop., ${ }^{4,10}$

As shown in these examples, the flexibility of the 3D screen allows the use of lesser animals for screening. Depending on the aims of the screen, fish other than sentinels are sampled, for example, colony fish or escapees. Some more specific PCR panels are used to investigate clinical cases. According to the prevalence and pathogenicity of zebrafish pathogens, a higher number of fish are tested for the more relevant pathogens. For example, $P$. tomentosa, M. marinum, and M. haemophilum are tested in more animals than the other pathogens. But since we confirmed that $P$. neurophilia was present in all our stock, we have not spent any more money testing for it.

Figure 5 is a list of cases describing how the 3D screen approach supports the decision-making process. It shows how the flexibility of the system can be tailored to the facility. In absence of pathogens, the comprehensive approach can help reducing cost. In case of contamination or of increased mortality rates, the choice of assay is essential to confirm diagnosis and to analyze the impact on the system and colonies. This flowchart orients veterinary investigation toward the most adapted test (bearing in mind cost and turnover) for a few clinical cases.

\section{Conclusion}

The 3D screen provides a robust process to adapt diagnostic methods to a particular situation. Not only screening one biotope or another, but also to tailor the PCR panel and to reduce the number of fish to sample. This flexibility is facilitated by the low cost of the sludge and water testing. In case of an outbreak, the 3D screen is a valuable tool to make a decision quickly. For the researcher, this approach of zebrafish health monitoring is an efficient means to define their colony's health status. This is becoming a requirement to share animals with collaborators ${ }^{26,27}$ and when presenting experimental data. 


\section{Acknowledgments}

The authors thank Alec Gallagher, Mollie Millington, the Aquatic team, and the Histopathology Laboratory of the Francis Crick Institute for their hard work; without them, they would not be able to monitor the fish health. In addition, Katy Murray and Chris Whipps have been very helpful in the development of this program. The authors are also thankful to James Baily, Johanna Baily, Emmanuel Leguay, Yolanda Saavedra Torres, and Carole Wilson for their help and input in constructive discussions.

\section{Disclosure Statement}

No competing financial interests exist.

\section{References}

1. FELASA working group on revision of guidelines for health monitoring of rodents and rabbits; Mähler Convenor M, Berard M, Feinstein R, Gallagher A, Illgen-Wilcke B, et al. FELASA recommendations for the health monitoring of mouse, rat, hamster, guinea pig and rabbit colonies in breeding and experimental units. Lab Anim 2014;48:178-192.

2. Kent ML, Feist SW, Harper C, Hoogstraten-Miller S, Law JM, Sánchez-Morgado JM, et al. Recommendations for control of pathogens and infectious diseases in fish research facilities. Comp Biochem Physiol C Toxicol Pharmacol 2009; 149:240-248.

3. Spagnoli ST, Xue L, Murray KN, Chow F, Kent ML. Pseudoloma neurophilia: A retrospective and descriptive study of nervous system and muscle infections, with new implications for pathogenesis and behavioral phenotypes. Zebrafish 2015;12:189-201.

4. Whipps CM, Dougan ST, Kent ML. Mycobacterium haemophilum infections of zebrafish (Danio rerio) in research facilities. FEMS Microbiol Lett 2007;270:21-26.

5. Spagnoli S, Xue L, Kent ML. The common neural parasite Pseudoloma neurophilia is associated with altered startle response habituation in adult zebrafish (Danio rerio): Implications for the zebrafish as a model organism. Behav Brain Res 2015;291:351-360.

6. Kent ML, Harper C, Wolf JC. Documented and potential research impacts of subclinical diseases in zebrafish. ILAR J 2012;53:126-134.

7. Murray KN, Peterson TS. Pathology in practice. P. tomentosa infection in zebrafish. J Am Vet Med Assoc 2015;246: 201-203.

8. Whipps CM, Matthews JL, Kent ML. Distribution and genetic characterization of Mycobacterium chelonae in laboratory zebrafish Danio rerio. Dis Aquat Organ 2008; $82: 45-54$.

9. Egg Bleaching. http://zebrafish.org/documents/protocols .php\# (Accessed November 30, 2015).

10. Watral V, Kent ML. Pathogenesis of Mycobacterium spp. in zebrafish (Danio rerio) from research facilities. Comp Biochem Physiol C Toxicol Pharmacol 2007;145:55-60.

11. Chow FW, Xue L, Kent ML. Retrospective study of the prevalence of Pseudoloma neurophilia shows male sex bias in zebrafish Danio rerio (Hamilton-Buchanan). J Fish Dis 2016;39:367-370.

12. Harper C, Lawrence C. The Laboratory Zebrafish. CRC Press, Boca Raton, FL, 2011.
13. Hawke JP, Kent M, Rogge M, Baumgartner W, Wiles J, Shelley J, et al. Edwardsiellosis caused by Edwardsiella ictaluri in laboratory populations of Zebrafish Danio rerio. J Aquat Anim Health 2013;25:171-183.

14. Coyne RS, Hannick L, Shanmugam D, Hostetler JB, Brami D, Joardar VS, et al. Comparative genomics of the pathogenic ciliate Ichthyophthirius multifiliis, its free-living relatives and a host species provide insights into adoption of a parasitic lifestyle and prospects for disease control. Genome Biol 2011;12:R100.

15. Velvet Disease (Piscinoodinium pillulare). https://zebrafish .org/health/diseaseManual.php\# (Accessed November 30, 2015).

16. Sanders JL, Lawrence C, Nichols DK, Brubaker JF, Peterson TS, Murray KN, et al. Pleistophora hyphessobryconis (Microsporidia) infecting zebrafish Danio rerio in research facilities. Dis Aquat Organ 2010;91: 47-56.

17. Moyer TR, Hunnicutt DW. Susceptibility of zebra fish Danio rerio to infection by Flavobacterium columnare and F. johnsoniae. Dis Aquat Organ 2007;76:39-44.

18. Crim MJ, Riley LK. Viral diseases in zebrafish: What is known and unknown. ILAR J 2012;53:135-143.

19. Foreyt WJ. Veterinary Parasitology Reference Manual, 5th Edition. Wiley-Blackwell, Ames, IA, 2001.

20. Kent ML, Bishop-Stewart JK, Matthews JL, Spitsbergen JM. Pseudocapillaria tomentosa, a nematode pathogen, and associated neoplasms of zebrafish (Danio rerio) kept in research colonies. Comp Med 2002;52:354-358.

21. Moravec F. Observations on the bionomy of the nematode Pseudocapillaria brevispicula (Linstow, 1873). Folia Parasitol 1983;30:229-241.

22. Whipps CM, Kent ML. Polymerase chain reaction detection of Pseudoloma neurophilia, a common microsporidian of zebrafish (Danio rerio) reared in research laboratories. J Am Assoc Lab Anim Sci 2006;45:36-39.

23. Whipps CM, Lieggi C, Wagner R. Mycobacteriosis in zebrafish colonies. ILAR J 2012;53:95-105.

24. Schroeder P, Mocho JP. A veterinary perspective on laboratory zebrafish welfare. Fish Vet J 2014;14:37-46.

25. Bacterial aerocystitis. https://zebrafish.org/health/disease Manual.php\# (Accessed November 30, 2015).

26. Lawrence C, Ennis DG, Harper C, Kent ML, Murray K, Sanders GE. The challenges of implementing pathogen control strategies for fishes used in biomedical research. Comp Biochem Physiol C Toxicol Pharmacol 2012;155:160-166.

27. Pritchett-Corning KR, Prins JB, Feinstein R, Goodwin J, Nicklas W, Riley L; Federation of Laboratory Animal Science Associations; American Association for Laboratory Animal Science. AALAS/FELASA Working Group on Health Monitoring of rodents for animal transfer. J Am Assoc Lab Anim Sci 2014;53:633-640.

Address correspondence to: Jean-Philippe Mocho, DVM, MRCVS, MVDr Mill Hill Laboratory The Francis Crick Institute The Ridgeway London NW7 1AA United Kingdom

E-mail: jpmocho@daniovet.com 